\title{
Filtering Antenna with Two-Octave Harmonic Suppression
}

\author{
Chun-Xu Mao, Steven Gao, Senior Member, IEEE, Yi Wang, Senior Member, IEEE, Zhiqun Cheng
}

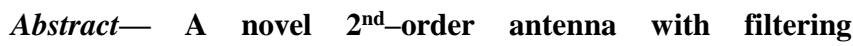
performance and two-octave harmonic suppression is proposed. In order to reduce the effects of the harmonics of the antenna, two types of antennas (PIFA and patch) with different resonant characteristics are integrated into the design. Compared with the traditional patch antennas, this integrated work can not only eliminate the high-order harmonics of the antenna but also improve the in-band bandwidth and frequency selectivity. The $2^{\text {nd }}$ and $4^{\text {th }}$-order harmonics of the patch are suppressed because of the detuned harmonic performance of the PIFA and patch. The $3^{\text {rd }}$-order harmonic is eliminated by integrating notch resonators in the PIFA. A prototype works at $2.4 \mathrm{GHz}$ is developed to demonstrate the PIFA-patch integration scheme. Measured and simulated results of antennas agree well with each other, demonstrating good performance of bandwidth, $2^{\text {nd }}$-order filtering, radiation and wideband harmonic suppression (up to 11 GHz).
\end{abstract}

Index Terms $-2^{\text {nd }}$-order filtering, harmonics suppression, patch antenna, planar inverted-F antenna.

\section{INTRODUCTION}

$\mathrm{M}$ ICROSTRIP antennas have been widely used in wireless communications systems. However, microstrip patch antennas suffer from problems such as narrow bandwidth and harmonics in the high-band. Traditionally, the bandwidth is broadened by adding an additional patch over the driven patch [1-2]. On the other hand, the filters are cascaded with the antennas in the communication systems for eliminating the influence of harmonics which are mainly generated by nonlinear microwave components and the spurious modes of the antennas [3].

In order to reduce the complexity and volume of the RF front-end, various integrated techniques have been adopted to suppress the harmonics. In [4]-[7], slots or shorted pins are inserted in the radiating element to produce mismatching at the given bands. In [8]-[10], periodic structures such as defected ground structures (DGS) are used to reduce the effects of the harmonics. Harmonics can also be reduced by placing a notch

This manuscript is submitted on December 20,2015. This work is supported by the project "DIFFERENT" funded by EC FP7 (grant no. 6069923). YW is supported by UK EPSRC under Contract EP/M013529/1.

C. Mao and S. Gao are with the School of Engineering and Digital Arts, University of Kent, UK. (e-mail: cm688@kent.ac.uk).

Y. Wang is with the Department of Engineering Science, University of Greenwich, UK.

Z. Cheng is with Hangzhou DianZi University, China.

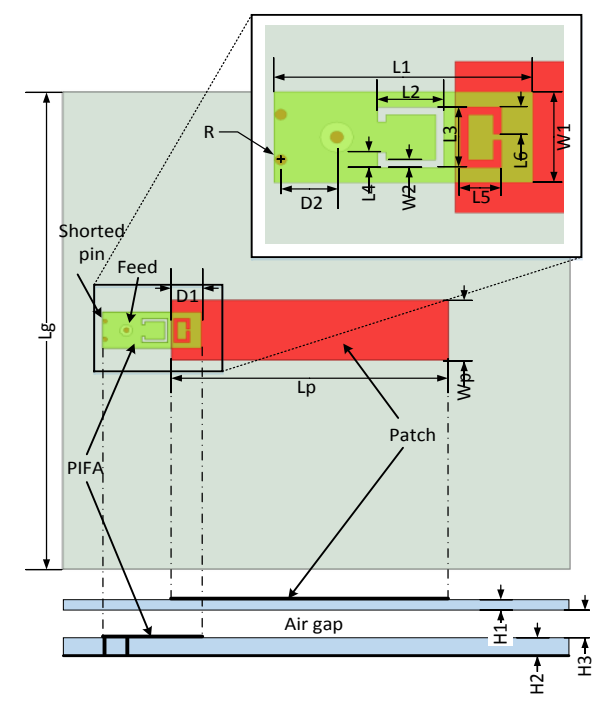

Fig.1. Configuration of the proposed PIFA-fed patch antenna.

resonator close to the feed [11]. However, most of the techniques presented so far are dealing with the $2^{\text {nd }}-$ order harmonics, the higher-order harmonics are rarely looked at. The other limitation of these works is the narrow bandwidth in-band. It is usually a challenge to achieve a multi-octave harmonic suppression because of the space limitation. In addition, the integration of filter and antenna can not only suppress the harmonics but also improve the in-band frequency performances such as bandwidth, frequency selectivity and gain response [12]-[17].

In this paper, a novel patch antenna is proposed. By coupling and feeding the patch using a planar inverted-F antenna (PIFA), $2^{\text {nd }}$-order frequency responses with improved bandwidth and selectivity are achieved. Moreover, the $2^{\text {nd }}, 3^{\text {rd }}$ and $4^{\text {th }}$-order harmonics over a two-octave band are significantly suppressed without incurring any additional circuits. The concept and design methodology are detailed. Measured results agree reasonably well with the simulations, demonstrating the proposed PIFA-fed patch antenna has good impedance bandwidth, frequency selectivity and broadband harmonic suppression.

\section{PIFA-FEd ANTENNA}

\section{A. Configuration}

Fig. 1 shows the configuration of the proposed PIFA-fed patch antenna. The patch is rectangular printed on the upper layer of the top substrate and the PIFA is printed on the upper 
TABLE I

PARAMETERS OF THE PROPOSED ANTENNA: (MM)

\begin{tabular}{ccccccccc}
\hline \hline Lg & Lp & Wp & H1 & H2 & H3 & $\mathrm{R}$ & L1 & L2 \\
80 & 43.6 & 10 & 0.813 & 1.525 & 4 & 0.35 & 15.7 & 4 \\
\hline L3 & L4 & L5 & L6 & W1 & W2 & D1 & D2 & \\
4 & 1 & 2.5 & 1.8 & 6 & 0.5 & 5.2 & 3.4 & \\
\hline \hline
\end{tabular}

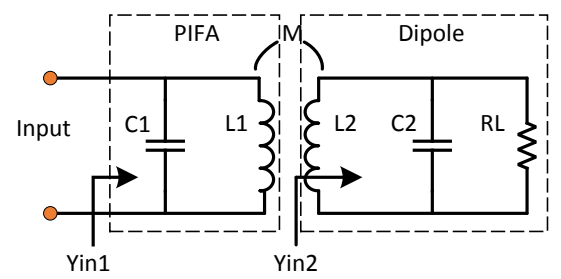

Fig. 2. Schematic equivalent circuit of the coupled PIFA-patch structure.

layer of the bottom substrate while the ground plane is printed on the lower layer of the bottom substrate. Between the two substrates, an air gap is inserted for improving the impedance matching. The PIFA is shorted to the ground through two pins at the one end. The PIFA and the patch have the same resonant frequency of $2.4 \mathrm{GHz}$ and they are coupled to generate a high-order antenna through electromagnetic coupling. This can result in improved bandwidth and frequency selectivity when compared with the traditional patch antenna. Moreover, two complementary split-ring resonators are embedded in the PIFA so as to suppress its $3^{\text {rd }}$-order harmonics. RO4003C substrate with a permittivity of 3.55 and loss tangent of 0.0027 is used in the design. The thicknesses of the top and the bottom substrates are $0.813 \mathrm{~mm}$ and $1.525 \mathrm{~mm}$. All the simulations are performed using High Frequency Structure Simulator (HFSS 15) and the optimized parameters are listed in Table I.

\section{B. Equivalent circuit and methodology}

Because the PIFA works at is odd modes $\left(f_{0}, 3 f_{0}, 5 f_{0} \ldots\right)$, it can be regarded as a quarter wavelength resonator. The patch antenna, however, works at its integral times of fundamental mode $\left(f_{0}, 2 f_{0}, 3 f_{0} \ldots\right)$ and can be equivalent to a half wavelength resonator. Thus, the proposed antenna can be equivalent as a $2^{\text {nd }}$-order resonant circuit, as shown in Fig. 2. The PIFA is represented by a lumped $L C$ resonator. The open-end with the length less than a quarter wavelength is equivalent as a capacitance $C$ and the short-end is equivalent as an inductance $L$. The patch antenna above the PIFA can be equivalent as an $R L C$ resonator, where the $R_{L}$ indicates the radiation resistance. When the PIFA and the patch are stacked and overlapped, electromagnetic coupling between them occurs, which is indicated using $M$ in the figure.

The resonant frequencies of the PIFA and the dipole are determined by adjusting the physical dimension of the PIFA and patch, respectively. The coupling strength is decided by tuning the air gap thickness and the overlap area between the PIFA and the dipole, related to DI in Fig. 1. In this design, the antenna is designed to operate at $2.4 \mathrm{GHz}$ and $L p=44 \mathrm{~mm}, L 1$ $=15.5 \mathrm{~mm}$ and $D l=5 \mathrm{~mm}$ are chosen as the original values.

\section{C. $2^{\text {nd }}$-order frequency response}

According to the equivalent circuit presented in Fig. 2, $2^{\text {nd }}-$ order frequency responses can be achieved for the proposed PIFA-fed patch antenna. Additionally, the bandwidth of the antenna can be adjusted by changing the coupling strength

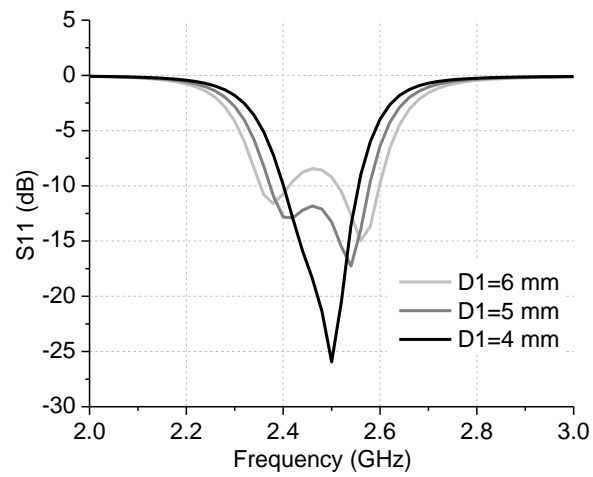

Fig. 3. The reflection coefficient with different $D 1$.

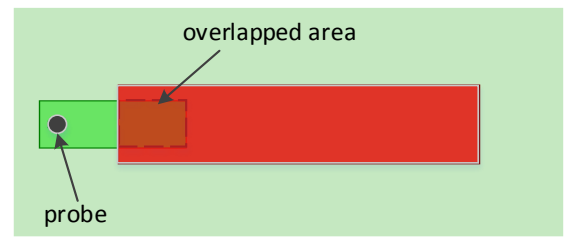

(a)

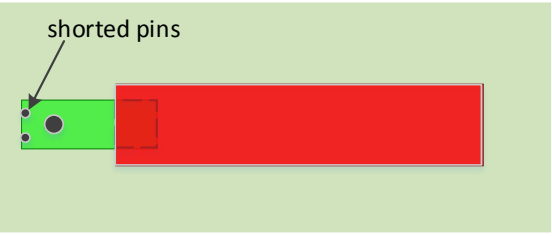

(b)

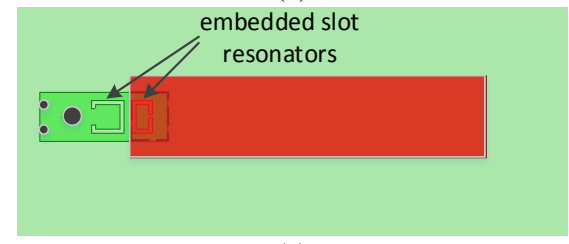

(c)

Fig. 4. Configuration of three types of patch antennas: (a) traditional microstrip-fed, Antenna-I; (b) PIFA-fed, Antenna-II; (c) PIFA-fed with embedded split-ring notch resonators, Antenna-III.

between the PIFA and the patch. Fig. 3 shows the simulated $\mathrm{S}_{11}$ with different overlapping areas as related to DI. As can be seen, $2^{\text {nd }}$-order frequency responses with two reflection zeros can be observed in the band, which is beneficial to improve the frequency selectivity and bandwidth. The two reflection zeros move close to each other as DI decreases, resulting in a narrower band.

\section{Harmonics Suppression}

One of the major advantages of this integrated antenna is the excellent harmonic suppression caused by their intrinsically different harmonic properties. It is well known the dipole is a half wavelength resonator with its harmonics at $2 f_{0}, 3 f_{0}, 4 f_{0} \ldots, f_{0}$ is the fundamental resonant frequency. However, the PIFA can be regarded as a quarter wavelength resonator and its harmonics locate at $3 f_{0}, 5 f_{0} \ldots$. Thus, when the PIFA and the patch are synchronically tuned at their fundamental frequency, the even-order harmonics of the dipole at $2 f_{0}, 4 f_{0} \ldots$ can be innately eliminated. To verify it, three type of patch antennas with different feeds are investigated, as the configurations shown in Fig. 4. Fig. 4(a) is a traditional patch fed by microstrip, denoted as Antenna-I. In Fig. 4(b), two shorted pins are drilled close to the feed point to form a PIFA, denoted as 


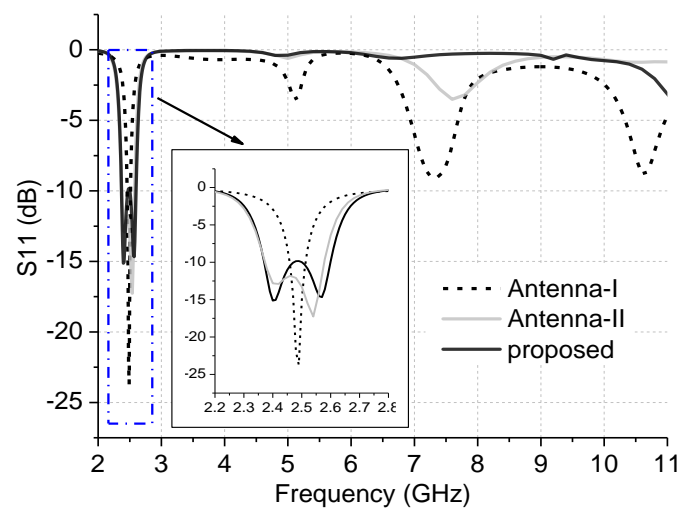

Fig. 5. Comparison of the $S_{11}$ of the three antennas.

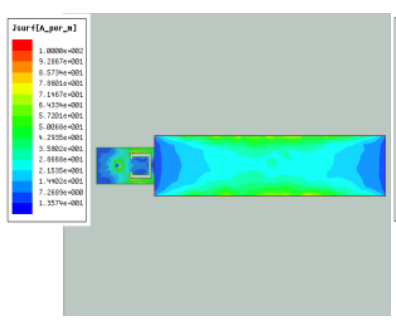

(a)

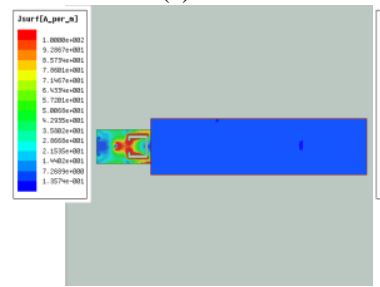

(c)

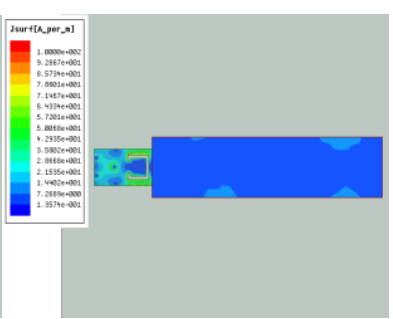

(b)

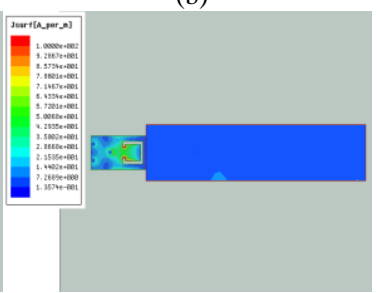

(d)
Fig. 6. The current distribution of the proposed at different frequencies: (a) $2.5 \mathrm{GHz}$, (b) $5 \mathrm{GHz}$, (c) $7.4 \mathrm{GHz}$, (d) $10.5 \mathrm{GHz}$.

Antenna-II. Fig. 4(c) is the proposed antenna, which is conceived by etching two split-ring slots in the PIFA of Antenna-II. The two slots produce resonant notches at $7.5 \mathrm{GHz}$ to suppress the $3^{\text {rd }}$-order harmonics. The lengths of the slots are approximately half of a wavelength at the resonant frequencies.

Fig. 5 compares the simulated reflection coefficients of the Antenna-I, Antenna-II and proposed antenna over a broad frequency range. The three antennas have the same working frequency at $2.5 \mathrm{GHz}$. However, they show very different higher-order harmonic responses. For Antenna-I, the $2^{\text {nd }}, 3^{\text {rd }}$ and $4^{\text {th }}$-order harmonics at $5,7.4$ and $10.5 \mathrm{GHz}$ can be clearly identified. For the Antenna-II, the $2^{\text {nd }}-$ and the $4^{\text {th }}-$ order harmonics at $5 \mathrm{GHz}$ and $10.5 \mathrm{GHz}$ are significantly suppressed due to the PIFA is used as the feed. However, the $3^{\text {rd }}$-order harmonic still exists. For proposed antenna, the $3^{\text {rd }}$-order harmonic at $7.4 \mathrm{GHz}$ is eliminated because of the split-ring notch resonators integrated into the PIFA. As can be seen, the proposed antenna exhibits a two-octave harmonic-free band up to $11 \mathrm{GHz}$. Another advantage of the proposed PIFA-fed patch antenna is that the operation bandwidth is significantly improved, as the inset shown in Fig. 5. It is observed that the two PIFA-fed antennas have two reflection zeros in the bands, contributing to improved bandwidths (220 MHz vs $70 \mathrm{MHz}$ ) and frequency selectivity.

The simulated current distribution of the antenna at 2.5, 5, 7.4 and $10.5 \mathrm{GHz}$ is shown in Fig. 6. As can be observed, the
TABLE II

COMPARISONS OF THE THREE ANTENNAS

\begin{tabular}{c|c|c|c|c}
\hline \hline \multirow{2}{*}{$\begin{array}{c}\text { Antenna } \\
\text { type }\end{array}$} & \multirow{2}{*}{$\begin{array}{c}\text { Fractional } \\
\text { bandwidth }\end{array}$} & \multicolumn{3}{|c}{ Harmonic suppression $\left(\left|\mathrm{S}_{11}\right|\right)$} \\
\cline { 3 - 5 } & $2^{\text {nd }}-$ order & $3^{\text {rd }}-$ order & $4^{\text {th }}$-order \\
\hline Antenna-I & $2.8 \%$ & $-3.6 \mathrm{~dB}$ & $-8.5 \mathrm{~dB}$ & $-8.5 \mathrm{~dB}$ \\
\hline Antenna-II & $8.8 \%$ & $-0.4 \mathrm{~dB}$ & $-3.5 \mathrm{~dB}$ & $-0.8 \mathrm{~dB}$ \\
\hline Proposed & $9.0 \%$ & $-0.3 \mathrm{~dB}$ & $-0.2 \mathrm{~dB}$ & $-1.2 \mathrm{~dB}$ \\
\hline \hline
\end{tabular}

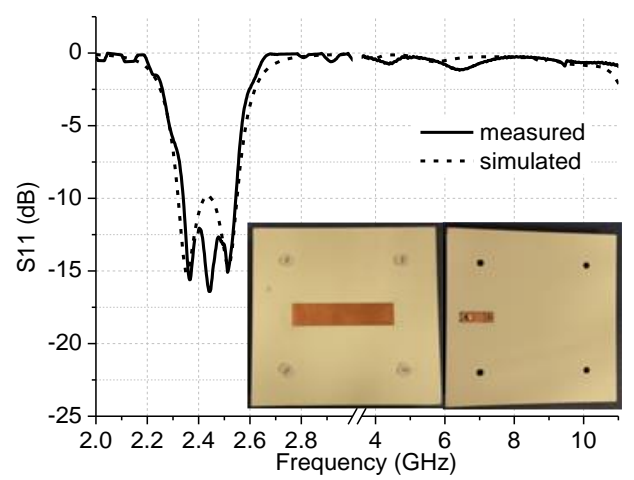

Fig. 7. Simulated and measured $S_{11}$ of the proposed PIFA-dipole element.

current on the antenna exhibits a sinusoidal distribution, indicating a radiation on the patch. However, very weak current on the patch can be observed. At $7.4 \mathrm{GHz}$, the current mainly concentrates around the slot resonators in the PIFA, causing a strong reflection at the input.

Table II summaries and compares the three antennas in terms of the bandwidth and harmonics suppression performance. As can be seen, the proposed antenna has an excellent out-of-band rejection with the $2^{\text {nd }}-, 3^{\text {rd }}$ and $4^{\text {th }}$-order harmonics significantly suppressed.

\section{RESULTS AND DISCUSSION}

Fig. 7 shows the simulated and measured S-parameters from 2 to $11 \mathrm{GHz}$. The measured result agrees well with the simulated one, showing an impedance matching bandwidth from 2.32 to $2.57 \mathrm{GHz}$. Out-of-band, the $2^{\text {nd }}, 3^{\text {rd }}$ and $4^{\text {th }}$ harmonics of the patch at around 5, 7.4 and $10.5 \mathrm{GHz}$ are significantly suppressed, contributing to an excellent harmonic suppression performance over a two-octave bandwidth (from 2.7 to $11 \mathrm{GHz}$ ).

Fig. 8 shows the simulated and measured normalized radiation patterns of the antenna. The measured patterns agree well with the simulations, exhibiting directional radiation pattern in broadside. The cross polarization discrimination (XPD) are better than $30 \mathrm{~dB}$ in both the $\mathrm{E}$ and $\mathrm{H}$ planes. The discrepancy of the backward patterns between the simulation and the measurement is caused by the absorber material mounted on the back of the antenna under the measurement.

Fig. 9 shows the simulated and measured gains of the proposed PIFA-fed antenna as a function of frequency. The measured result exhibits a flat gain response of $6.7 \mathrm{dBi}$ at around $2.5 \mathrm{GHz}$, which is slightly lower than the simulated 7.2 $\mathrm{dBi}$. Out of the band, the measured gain is lower than $-7 \mathrm{dBi}$ from 2.8 to $10.5 \mathrm{GHz}$, demonstrating that the PIFA-fed patch antenna exhibits an excellent harmonic suppression performance over a wideband with the $2^{\text {nd }}, 3^{\text {rd }}$ and $4^{\text {th }}$ harmonics of the patch are significantly suppressed. 


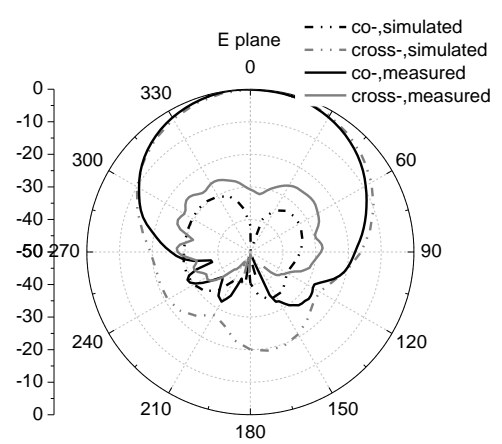

(a)

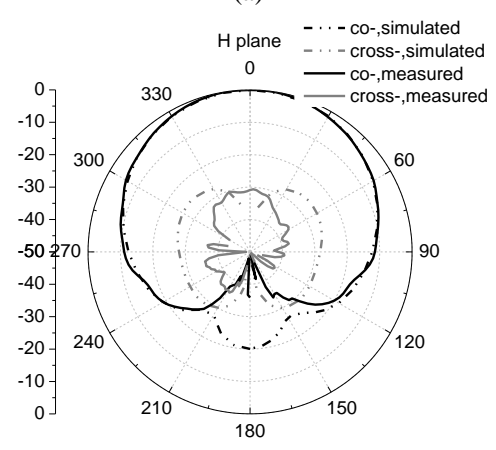

(b)

Fig. 8. The normalized simulated and measured radiation patterns of the element at $2.5 \mathrm{GHz}$ : (a) E plane, (b) $\mathrm{H}$ plane.

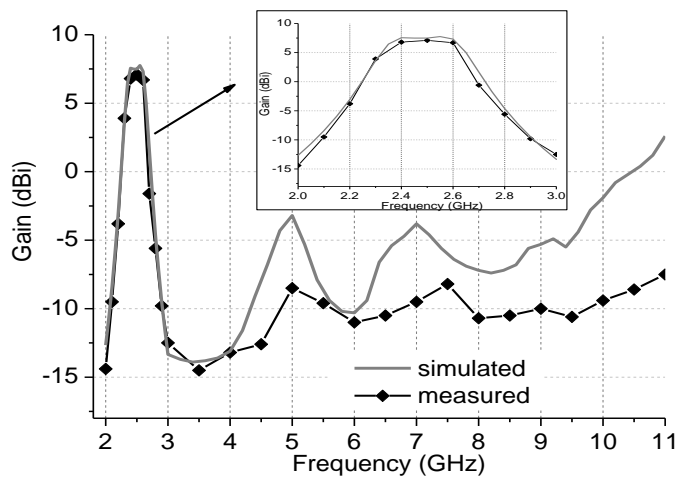

Fig. 9. Simulated and measured gain of the PIFA-fed patch antenna.

Table III compares the proposed antenna in this paper with several other reported works with harmonic suppression capabilities in [6], [9]-[11]. The comparison mainly focuses on the orders of in-band responses, the order of harmonics suppressed and suppression performance. From the comparison, we can see the proposed PIFA-fed patch antenna has a higher-order in-band frequency response and a better harmonic suppression performance with $2^{\text {nd }}, 3^{\text {rd }}$ and $4^{\text {th }}$ harmonics significantly suppressed.

\section{CONCLUSION}

In this paper, a novel $2^{\text {nd }}$-order PIFA-fed patch antenna is proposed. The antenna is achieved by electromagnetically coupling a PIFA to a patch. This integrated design not only improves the bandwidth of the patch, but also the out-of-band rejection performance. The $2^{\text {nd }}, 3^{\text {rd }}$, and $4^{\text {th }}$-order harmonics of the patch are significantly suppressed by employing the different resonant characteristics of the patch and the PIFA. More than two-octave harmonic suppression bandwidth is
TABLE III COMPARISON WITH OTHER HARMONIC SUPPRESSION ANTENNAS

\begin{tabular}{ccccc}
\hline \hline $\begin{array}{c}\text { Types of } \\
\text { antennas }\end{array}$ & $\begin{array}{c}\text { Operation } \\
\text { frequency }\end{array}$ & $\begin{array}{c}\text { Orders of } \\
\text { responses }\end{array}$ & $\begin{array}{c}\text { harmonics } \\
\text { suppressed }\end{array}$ & $\begin{array}{c}\text { Rejection } \\
\text { performance }\end{array}$ \\
\hline Ref. [6] & $0.9 \mathrm{GHz}$ & $1 \mathrm{st}$ & $2^{\text {nd }}, 3^{\text {rd }}$ & $-1.3 \mathrm{~dB}$ \\
Ref. [9] & $3.1 \mathrm{GHz}$ & $1 \mathrm{st}$ & $2^{\text {nd }}, 3^{\text {rd }}$ & $-2.5 \mathrm{~dB}$ \\
Ref. [10] & $2.45 \mathrm{GHz}$ & $1 \mathrm{st}$ & $2^{\text {nd }}, 3^{\text {rd }}$ & $-3 \mathrm{~dB}$ \\
Ref. [11] & $2.2 \mathrm{GHz}$ & $1 \mathrm{st}$ & $2^{\text {nd }}, 3^{\text {rd }}$ & $-4 \mathrm{~dB}$ \\
This work & $2.5 \mathrm{GHz}$ & $2 \mathrm{nd}$ & $2^{\text {nd }}, 3^{\text {rd }}, 4^{\text {th }}$ & $-1 \mathrm{~dB}$ \\
\hline \hline
\end{tabular}

achieved. The concept has been experimentally verified, and the measured results have shown excellent performance in terms of impedance matching, radiation patterns, gains and wideband harmonic suppression.

\section{REFERENCES}

[1] X. Qu, S. S. Zhong, Y. M. Zhang and W. Wang, "Design of an S/X dual-band dual-polarised microstrip antenna array for SAR applications," IET Microw. Antennas Propag., vol. 1, pp. 513-517, 2007.

[2] F. Croq and D. M. Pozar, "Millimeter-wave design of wide-band aperture-coupled stacked microstrip antennas," IEEE Trans. Antennas and Propag., vol. 39, no. 12, pp. 1770-1776, Dec. 1991.

[3] Y. J. Ren, M. Farooqui and K. Chang, "A compact dual-frequency rectifying antenna with high-orders harmonic-rejection," IEEE Trans. Antennas and Propag., vol. 55, no. 7, pp. 2110-2113, Jul. 2007.

[4] S. Kwon, B. M. Lee, Y. J. Yoon, W. Y. Song and J. G. Yook, "A harmonic suppression antenna for an active integrated antenna," IEEE Antenna Wireless Propag. Lett., vol. 13, no. 2, pp. 54-56, 2003.

[5] F. J. Huang, T. C. Yo, C. M. Lee and C. H. Luo, "Design of circular polarization antenna with harmonic suppression for rectenna application," IEEE Antenna Wireless Propag. Lett., vol. 11, no. 2, pp. 592-595, 2012.

[6] H. Liu, Z. Li, X. Sun and J. Mao, "Harmonic suppression with photonic bandgap and defected ground structure for a microstrip patch antenna," IEEE Antenna Wireless Propag. Lett., vol. 15, no. 2, pp. 55-56, 2005.

[7] Q. X. Chu, C. X. Mao and H. Zhu, "A compact notched band UWB slot antenna with sharp selectivity and controllable bandwidth," IEEE Trans. Antennas and Propag., vol. 61, no. 8, pp. 3961-3966, Aug. 2013.

[8] Y. Xu, S. Gong and Y. Guan, "Coaxially fed microstrip antenna for harmonic suppression," Electron. Lett., vol. 48, no. 15, pp. 895-896, 2012.

[9] S. Biswas, D. Guha and C. Kumar, "Control of higher harmonics and their radiations in microstrip antennas using compact defected ground structures," IEEE Trans. Antennas and Propag., vol. 61, no. 6, pp. 3349-3353, Jun. 2013.

[10] C. Y. D. Sim, M. H. Chang and B. Y. Chen, "Microstrip-fed ring slot antenna with wideband harmonic suppression," IEEE Trans. Antennas and Propag., vol. 62, no. 9, pp. 4828-4832, Sep. 2014.

[11] L. Inclan, J. L. Wazquez and E. Rajo, "Proximity coupled microstrip patch antenna with reduced harmonic radiation," IEEE Trans. Antennas and Propag., vol. 57, no. 1, pp. 27-32, Jan. 2009.

[12] C. X. Mao, S. Gao, Y. Wang, F. Qin and Q. X. Chu, "Multi-mode resonator-fed dual polarized antenna array with enhanced bandwidth and selectivity," IEEE Trans. Antennas and Propag., vol. 63, no. 12, pp. 5492-5499, Dec. 2015.

[13] Y. Yusuf and X. Gong, "Compact Low-Loss Integration of High-Q 3-D Filters with Highly Efficient Antennas," IEEE Trans. Microw. Theory Tech., vol. 59, no. 4, pp. 857-865, Apr. 2011.

[14] C. T. Chuang and S. J. Chung, "Synthesis and Design of a New Printed Filtering Antenna," IEEE Trans. Antennas and Propag., vol. 59, no. 3, pp. 1036-1042, Mar. 2011.

[15] G. Q. Luo, W. Hong, H. J. Tang, J. X. Chen, X. X. Yin, Z. Q. Kuai, and K. $\mathrm{Wu}$, "Filtenna consisting of horn antenna and substrate integrated waveguide cavity FSS," IEEE Trans. Antennas Propag., vol. 55, pp. 92-98, 2007.

[16] M. Barbuto, F. Trotta, F. Bilotti, and A. Toscano, "A combined bandpass filter and polarization transformer for horn antennas," IEEE Antennas Wireless Propag. Lett., vol. 12, pp. 1065-1068, 2013.

[17] C. Yu, W. Hong, Z. Kuai, and H. Wang, "Ku-band linearly polarized omnidirectional planar filtenna," IEEE Antennas Wireless Propag. Lett., vol. 11, pp. 310-313, 2012. 